\title{
SISTEM PENENTUAN KEPUTUSAN PEMILIHAN JURUSAN PADA SISWA SMAN 4 BANJARBARU MENGGUNAKAN METODE SIMPLE ADDITIVE WEIGHTING (SAW)
}

\author{
Fakultas Teknologi Informasi \\ Universitas Islam Kalimantan Muhammad Arsyad al Banjari Banjarmasin \\ Al Fath Riza Kholdani \\ (kholdanialfath@gmail.com)
}

\begin{abstract}
ABSTRAK
Sistem penjurusan pada SMAN 4 Banjarbaru selama ini masih masih bersifat subjektif dan pilihan siswa sendiri, akhirnya pembagian jumlah siswa pada setiap kelas berdasarkan jurusan tidak berimbang. Penelitian ini menganalisa dan membuat perangkat lunak sistem penentuan keputusan jurusan menggunakan metode Simple Additive Weight (SAW) untuk mendapatkan proses pembobotan dalam penentuan keputusan yang terkomputerisasi. Perhitungan untuk pembobotan berdasarkan kriteria nilai siswa, ekstrakurikuler, kerajinan, nilai test dan kelakuan. Nilai akhir dari SAW nantinya dikonversi menyesuaikan jurusan yang akan ditentukan baik IPA, IPS dan Bahasa.
\end{abstract}

Kata kunci : SAW, SPK, Jurusan

\section{PENDAHULUAN}

Pemanfaatan ilmu pengetahuan dan teknologi berkembang dengan sangat cepat dan menghasilkan inovasi baru yang harus di imbangi dengan kemampuan beradaptasi terhadap kondisi tersebut, Salah satu implementasinya adalah sistem penentuan keputusan. Sistem Penentuan Keputusan kiranya adalah sekumpulan perintah komputer yang terintegrasi dengan mengijinkan seorang decisionmaker untuk berinteraksi langsung dengan komputer, agar menghasilkan informasi yang berguna dalam penentuan sebuah keputusan. Menurut Moore dan Chang, SPK dapat digambarkan sebagai sistem yang berkemampuan mendukung analisis ad hoc data, dan pemodelan keputusan, berorientasi keputusan, orientasi perencanaan masa depan, dan digunakan pada saat-saat yang tidak biasa.

Sistem Penentuan Keputusan (SPK) diharapkan dapat menghindarkan hasil yang subjektif dan dapat membantu sekolah dalam memutuskan jurusan para siswa/siswi. SPK merupakan suatu sistem menggunakan model yang dibangun untuk membantu menyelesaikan masalah-masalah penentuan jurusan. Menurut Keen dan Scoot Morton Sistem Penentuan Keputusan salah satu penggabungan sumber-sumber kecerdasan individu dengan kemampuan komponen komputer untuk memperbaiki kualitas keputusan. Sistem Penentuan Keputusan merupakan salah satu sistem informasi berbasis komputer untuk pimpinan pengambilan keputusan yang menangani masalah 
Metode Simple Additive Weighting (SAW) sering dikenal dengan istilah metode penjumlahan terbobot. Konsep dasar dalam menggunakan metode SAW dengan cara mencari penjumlahan terbobot dari rating kinerja pada setiap alternatif pada semua atribut. Metode SAW memerlukan proses normalisasi matriks keputusan ke skala yang dapat diperbandingkan dengan semua rating alternatif yang ada.

Sekolah SMA Negeri 4 Banjarbaru dalam penyajian dan pengolahan data siswa untuk menentukan jurusan belum terkomputerisasi. penentuan jurusan yang diambil saat ini sangat subyektif dan berdasarkan keinginan siswa sendiri. Hal tersebut menyebabkan ketidak seimbangan jumlah siswa dalam setiap jurusan. Jumlah jurusan yang ada di SMA Negeri 4 Banjarbaru terdiri dari tiga jurusan yaitu jurusan Ilmu Pengetahuan Alam (IPA), Ilmu Pengetahuan Sosial (IPS) dan Bahasa. Pilihan masing-masing jurusan didasarkan pada ketentuan dari nilai yang diisyaratkan pada masing-masing jenis jurusan.

\section{METODE, ANALISA DAN DESAIN}

Penentuan tiap kriteria yang digunakan dalam menerapkan metode SAW yaitu nilai raport siswa, ekstrakurikuler, Keaktifan, Nilai Test serta Etika. Bobot merupakan prioritas jika bernilai $1=$ sangat kurang, $2=$ kurang, 3 =cukup, 4=cukup baik, 5=baik.

2.1 Tabel Kriteria Pembobotan

\begin{tabular}{|c|l|c|}
\hline No & Kriteria & BOBOT \\
\hline 1 & Nilai Siswa & $40-60=1$ \\
& & $61-70=2$ \\
& & $71-80=3$ \\
& & $81-90=4$ \\
& & $91-100=5$ \\
\hline
\end{tabular}

\begin{tabular}{|c|l|c|}
\hline 2 & Eksul siswa & $40-60=1$ \\
& & $61-70=2$ \\
& & $71=80=3$ \\
& & $81-90=4$ \\
& & $91-100=5$ \\
\hline 3 & Kerajinan & $40-60=1$ \\
& & $61-70=2$ \\
& & $71=80=3$ \\
& & $81-90=4$ \\
& & $91-100=5$ \\
\hline 4 & Nilai test & $40-60=1$ \\
& & $61-70=2$ \\
& & $71=80=3$ \\
& & $81-90=4$ \\
& & $91-100=5$ \\
\hline 5 & Kelakuan & $40-60=1$ \\
& & $61-70=2$ \\
& & $71=80=3$ \\
& & $81-90=4$ \\
& & $91-100=5$ \\
\hline
\end{tabular}

Dalam menentukan keputusan jurusan, penilain jurusan berdasarkan prosentase hasil perhitungan pembobotan dalam SAW. Berikut tabel penentuan jurusan:

Tabel 2.2 Keputusan Jurusan

\begin{tabular}{|c|c|c|}
\hline NO & JURSAN & NILAI \\
\hline 1 & IPA & $40 \%$ \\
\hline 2 & IPS & $35 \%$ \\
\hline 3 & BAHASA & $25 \%$ \\
\hline
\end{tabular}

\subsection{Desain Pemodelan Data}

Proses dalam SPK digambarkan dalam bentuk pemodelan visual dengan menggunakan Unified Modelling Language (UML). UML adalah salah satu alat bantu untuk pengembangan sistem yang berorientasi objek karena menyediakan bahasa pemodelan visual yang memungkinkan untuk membuat cetak biru (blueprint) visi dalam bentuk yang baku, mudah dimengerti dan dilengkapi dengan mekanisme yang efektif untuk berbagi rancangan. Dengan UML, desainer dapat melihat konsep global suatu desain. 


\section{1.ditrolse Case}

Use case diagram digunakan untuk memodelkan alur proses berdasârkan perspektif "pengguna sistem. Berikut merupakan use case diagram yang digunakan untuk perạñgkat lunak.

\section{Squence Diagram SAW}

Sequence ini untuk melakukan proses perhitungan SAW. User memulai dengan memilih menu. Kemudian menginput data setelah itu sistem melakukan proses perhitungan dan sistem akäm menampilkan hasil perhitungan, kemudian data tersebut di simpan ke dalam basis data.

T

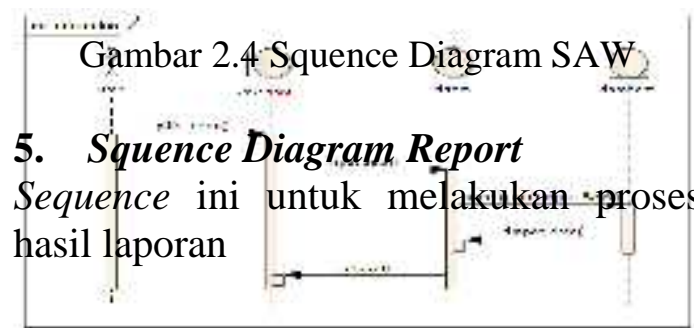

\section{uc Primgry use cases 2.2 Squence Diagram Login}

\section{Squence Diagram Input Login}

Sequence ini untuk melakukan proses memasukkan data siswa yang ditakukan

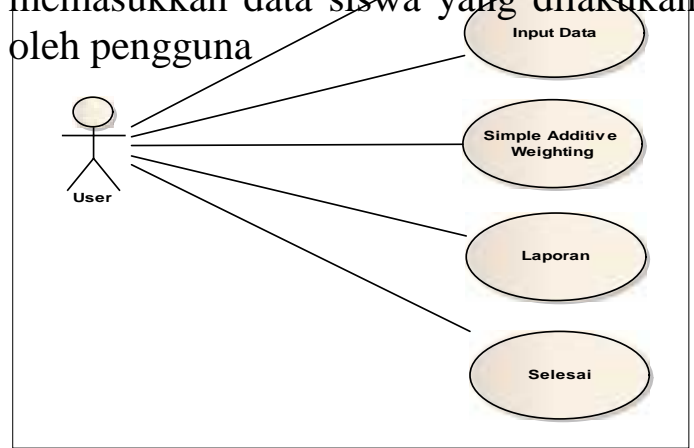

Gambar 2.3 Squence Diagram Input

\footnotetext{
Gambar 2.5 Squence Diagram Laporán

6. Squence "Diagram Finish

Sequence ini untuk|melakakan proses hasil selesai
}

Gambar 2.5 Squence Diagram Finish

\subsection{Desain Diagram Arsitektur}

Sistem penentuan keputusan pemilihan jurusan siswa siswi di SMA Negeri 4 Banjarbaru dengan metode

Jurnal Ilmiah “Technologia” 


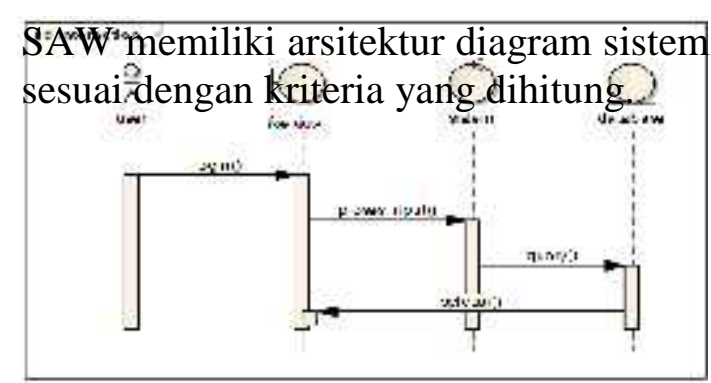

Gambar 2.5 Arsitektur Diagram

\subsection{Desain Basis Data}

Desain database merupakan rancangan struktur database berupa beberapa tabel yang mendukung untuk proses SAW.

1. Tabel Pengguna

Nama Tabel : Tuser

Fungsi : Informasi login

Kunci Utama : User

Tabel 2.2 Tabel Pengguna

\begin{tabular}{|l|l|l|}
\hline $\begin{array}{c}\text { Nama } \\
\text { Field }\end{array}$ & \multicolumn{1}{|c|}{$\begin{array}{c}\text { Tipe } \\
\text { Data }\end{array}$} & \multicolumn{1}{|c|}{ Keterangan } \\
\hline User & Text (6) & Nama User (PK) \\
\hline Password & Text (10) & Password \\
\hline
\end{tabular}

2. Tabel Siswa

Nama Tabel : TSiswa

Fungsi : Informasi Siswa

Kunci Utama : NoInduk

Tabel 2.3 Tabel Siswa

\begin{tabular}{|l|l|l|}
\hline Nama Field & $\begin{array}{c}\text { Tipe } \\
\text { Data }\end{array}$ & Keterangan \\
\hline NoInduk & Text (6) & $\begin{array}{l}\text { Nomor Induk } \\
(\text { PK) }\end{array}$ \\
\hline Nama Siswa & Text (25) & Nama Siswa \\
\hline
\end{tabular}

3. Tabel Nilai Kriteria

Nama Tabel : TNilai Kriteria

Fungsi : Nilai Kriteria Siswa

Kunci Utama : KdKrit
Tabel 2.4Tabel Nilai Kriteria

\begin{tabular}{|l|l|l|}
\hline \multicolumn{1}{|c|}{$\begin{array}{c}\text { Nama } \\
\text { Field }\end{array}$} & \multicolumn{1}{c|}{$\begin{array}{c}\text { Tipe } \\
\text { Data }\end{array}$} & \multicolumn{1}{|c|}{ Keterangan } \\
\hline KdKrit & Text (6) & Kode Nilai (PK) \\
\hline $\begin{array}{l}\text { Nilai } \\
\text { Pelajaran }\end{array}$ & Text (4) & Nilai Pelajaran \\
\hline $\begin{array}{l}\text { Nilai } \\
\text { Ekskul }\end{array}$ & Text (4) & $\begin{array}{l}\text { Nilai } \\
\text { Ekstrakurikuler }\end{array}$ \\
\hline Kelakuan & Text (4) & Nilai Kelakuan \\
\hline NoInduk & Text (6) & Nomor Induk (FK) \\
\hline
\end{tabular}

4. Tabel soal

Nama Tabel : TSoal

Fungsi : Informasi Soal Test

Kunci Utama : KdSoal

Tabel 2.5 Tabel Soal

\begin{tabular}{|l|l|l|}
\hline $\begin{array}{l}\text { Nama } \\
\text { Field }\end{array}$ & $\begin{array}{l}\text { Tipe } \\
\text { Data }\end{array}$ & Keterangan \\
\hline KdSoal & Text (6) & Kode Nilai (PK) \\
\hline Soal test & Text (4) & Memasukan soal \\
\hline NoInduk & Text (6) & Nomor Induk (FK) \\
\hline
\end{tabular}

5. Tabel Hasil Proses SAW

Nama Tabel : TNilaiSAW

Fungsi : Hasil Nilai Siswa

Kunci Utama : KdSAW

Tabel 2.6 Tabel Nilai Hasil Proses SAW

\begin{tabular}{|l|l|l|}
$\begin{array}{l}\text { Nama } \\
\text { Field }\end{array}$ & $\begin{array}{l}\text { Tipe } \\
\text { Data }\end{array}$ & Keterangan \\
\hline KdSAW & Text (6) & Kode Nilai (PK) \\
\hline $\begin{array}{l}\text { Nilai } \\
\text { Pelajaran }\end{array}$ & Text (4) & Nilai Pelajaran \\
\hline $\begin{array}{l}\text { Nilai } \\
\text { Ekskul }\end{array}$ & Text (4) & $\begin{array}{l}\text { Nilai } \\
\text { Ekstrakulikuler }\end{array}$ \\
\hline Kelakuan & Text (4) & Nilai Kelakuan \\
\hline Vn & Text (4) & Nilai Proses SAW \\
\hline NoInduk & Text (6) & Nomor Induk (FK) \\
\hline
\end{tabular}

\section{IMPLEMENTASI SISTEM}

\subsection{Perhitungan Pembobotan}

Adapun kriteria yang digunakan dalam penetapan pemilihan jurusan siswa di SMA Negeri 4 Banjarbaru dengan metode SAW (Simple Additive Weighting) yaitu : Nilai Siswa, Ekskul Siswa, Kelakuan Siswa, Kerajinan Siswa, Nilai Test Siswa sesuai Tabel 2.1 maka Hasil penilaian dari table penilaian 
alternatif didapat bentuk matriks keputusan seperti pada tabel berikut:

Tabel 3.1 Keputusan

\begin{tabular}{|c|c|c|c|c|c|c|c|c|}
\hline \multicolumn{9}{|c|}{ Kriteria } \\
\hline ż & 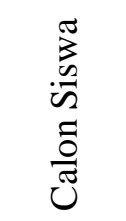 & 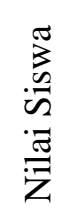 & $\begin{array}{l}\overline{\vec{a}} \\
\frac{\Delta}{I}\end{array}$ & 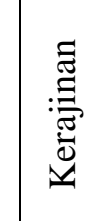 & $\begin{array}{l}\stackrel{\vec{n}}{\oplus} \\
\stackrel{\vec{n}}{\vec{z}}\end{array}$ & 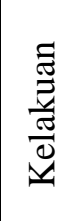 & 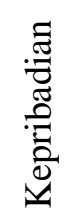 & 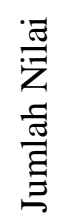 \\
\hline 1 & CS001 & 4 & 1 & 2 & 1 & 4 & 3 & 15 \\
\hline 2 & $\mathrm{CSO02}$ & 3 & 4 & 2 & 5 & 4 & 3 & 21 \\
\hline 3 & $\mathrm{CSO03}$ & 3 & 4 & 2 & 5 & 4 & 3 & 21 \\
\hline 4 & CSO04 & 3 & 3 & 2 & 3 & 4 & 3 & 18 \\
\hline 5 & CS005 & 4 & 4 & 2 & 5 & 4 & 3 & 22 \\
\hline 6 & CS006 & 3 & 2 & 2 & 3 & 4 & 3 & 17 \\
\hline 7 & CS007 & 3 & 4 & 2 & 5 & 4 & 2 & 20 \\
\hline 8 & CS008 & 3 & 2 & 2 & 3 & 4 & 3 & 17 \\
\hline 9 & CS009 & 3 & 1 & 2 & 3 & 4 & 3 & 16 \\
\hline 10 & \multicolumn{3}{|c|}{ CSO19 mant 4} & $n^{2}$ & 1). 5 & $14 \operatorname{lng}$ & 3. & 22 \\
\hline & \multicolumn{2}{|c|}{ ermudiani! } & $\begin{array}{l}\text { 1.ono } \\
\text { Ihasil } \\
\text { dibou }\end{array}$ & 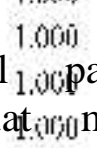 & $\begin{array}{l}\text { bijo } \\
\text { ala } \\
\text { nenjaj }\end{array}$ & $\begin{array}{l}\text { 1.joo } \\
\text { tabel }\end{array}$ & & \\
\hline & \multicolumn{2}{|c|}{ keputusamise } & bagai & berrik & utoin? & 1. 100 & & \\
\hline & & 0.300 & 1.0(ii) & i). $6 \mathrm{ij} 0$ & 1.000 & & \\
\hline & \multicolumn{2}{|c|}{0.760} & 1.600 & 1.000 & (O10) & 1. 1000 & & \\
\hline & \multicolumn{2}{|c|}{$0.7 \varsigma 0$} & $(1.50(10)$ & $1 \% j$ & 0.5001 & $1.0010 ;$ & & \\
\hline & \multicolumn{2}{|c|}{0.750} & $(1.25 \%$ & 1. 1100 & 0.6001 & 1.00\%) & & \\
\hline & \multicolumn{2}{|c|}{1.0000} & (6)0 & 10 (iij & $\sin 0$ & 1.000 & & \\
\hline
\end{tabular}

Gambar 3.1 Matriks Keputusan

Setelah mendapatkan matriks keputusan, selanjutnya membuat matriks ternormalisasi ( $\mathrm{R})$ dengan melakukan perhitungan sebagai berikut:

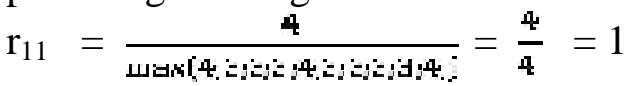

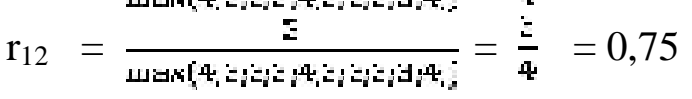

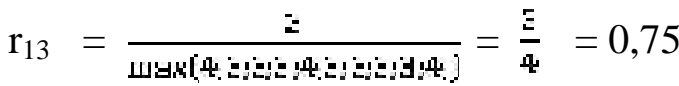

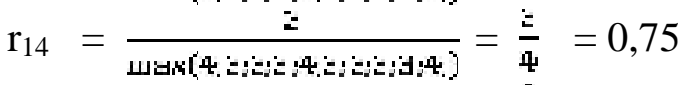

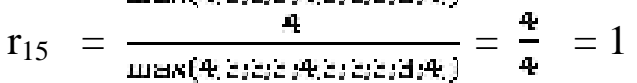

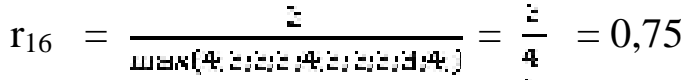

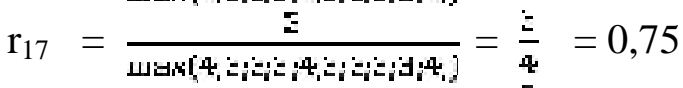

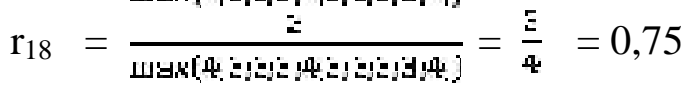

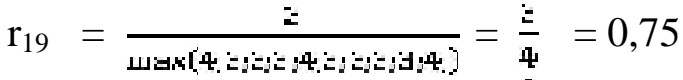

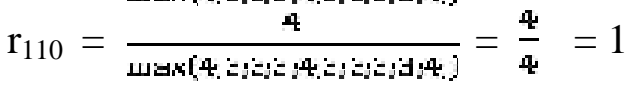

Seterusnya sehingga hasil dari seluruh perhitungan tersebut diperoleh matriks ternormalisasi (R) seperti dalam tabel berikut:

\begin{tabular}{|c|c|c|c|c|c|c|}
\hline \multicolumn{7}{|c|}{ Normalisasi } \\
\hline z & 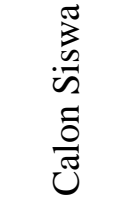 & 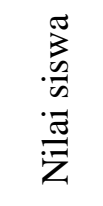 & $\begin{array}{l}\overline{\vec{n}} \\
\frac{\vec{v}}{0}\end{array}$ & 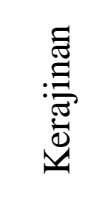 & $\begin{array}{l}\vec{\Phi} \\
\stackrel{\vec{\Xi}}{\vec{Z}} \\
\stackrel{\vec{Z}}{\Xi}\end{array}$ & $\begin{array}{l}\tilde{J} \\
\frac{\tilde{J}}{\sigma} \\
\frac{\vec{\sigma}}{d}\end{array}$ \\
\hline 1 & CS001 & 1.000 & 0.250 & 1.000 & 0.200 & 1.000 \\
\hline 2 & CSO02 & 0.750 & 1.000 & 1.000 & 1.000 & 1.000 \\
\hline 3 & $\mathrm{CSO} 03$ & 0.750 & 1.000 & 1.000 & 1.000 & 1.000 \\
\hline 4 & CS004 & 0.750 & 0.750 & 1.000 & 0.600 & 1.000 \\
\hline 5 & CS005 & 1.000 & 1.000 & 1.000 & 1.000 & 1.000 \\
\hline 6 & CS006 & 0.750 & 0.500 & 1.000 & 0.600 & 1.000 \\
\hline 7 & CS007 & 0.750 & 1.000 & 1.000 & 1.000 & 1.000 \\
\hline 8 & CS008 & 0.750 & 0.500 & 1.000 & 0.600 & 1.000 \\
\hline 9 & CS009 & 0.750 & 0.250 & 1.000 & 0.600 & 1.000 \\
\hline 10 & CS010 & 1.000 & 1.000 & 1.000 & 1.000 & 1.000 \\
\hline
\end{tabular}

Tabel 3.2 Matriks Ternormalisasi

Setelah- menghitung $4 \mathrm{R}$ adalant bentuk matriks ternofmảlisasi $4^{4}$ sebaga đa berikut :

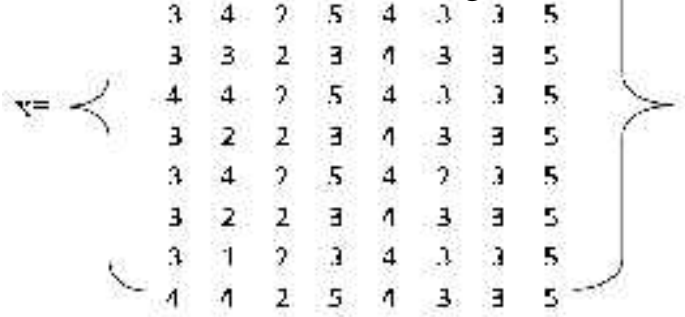


Gambar 3.2 Matriks Normalisasi

Hasil akhir diperoleh dari proses perangkingan yaitu penjumlahan dari perkalian matriks ternormalisasi $\mathrm{R}$ dengan vektor bobot sehingga diperoleh nilai terbesar yang dipilih sebagai alternatif terbaik sebagai solusi berdasarkan persamaan berikut :

$\mathrm{V}_{1}=(0,118 * 1)+(0,044 * 0,250)+$ $(0,294 * 1)+(0,035 * 0,2)+(0,235 * 1)=0.726$

$\mathrm{V}_{2}=(0.088 * 0,75)+(0,176 * 1)+$ $(0,294 * 1)+(0,176 * 1)+\left(0,235^{*} 1\right)=0.971$

$\mathrm{V}_{3}=\left(0,088^{*} 0,75\right)+(0,176 * 1)+$ $(0,294 * 1)+(0,176 * 0,2)+(0,235 * 1)=0.971$

$\mathrm{V}_{4}=(0,088 * 75)+(0,132 * 0,75)+$ $(0,294 * 1)+(0,106 * 0,6)+(0,235 * 1)=0.856$

$\mathrm{V}_{5}=\left(0,118^{*} 1\right)+\left(0,176^{*} 1\right)+$ $(0,294 * 1)+\left(0,176^{*} 1\right)+\left(0,235^{*} 1\right)=1$

$\mathrm{V}_{6}=(0,088 * 0,75)+(0,088 * 0,50)$ $+(0,294 * 1)+(0,106 * 0,6)+(0,235 * 1)=0.812$

$\mathrm{V}_{7}=\left(0,088^{*} 0,75\right)+(0,176 * 1)+$ $(0,294 * 1)+(0,176 * 1)+\left(0,235^{*} 1\right)=0.971$

$\mathrm{V}_{8}=(0,069 * 0,75)+(0,088 * 0,5)+$ $(0,294 * 1)+(0,106 * 0,6)+(0,235 * 1)=0.812$

$\mathrm{V}_{9}=(0,088 * 0,75)+(0,044 * 0,250)$ $+(0,294 * 1)+(0,106 * 0,6)+(0,235 * 1)=0.768$

$\mathrm{V}_{10}=(0,118 * 1)+(0,176 * 1)+(0,294 * 1)$ $+(0,176 * 1)+\left(0,235^{*} 1\right)+(0,172 * 1)=1$

\subsection{Hasil Aplikasi}

1. Menu login

Login digunakan oleh admin untuk masuk kedalam sistem bertujuan

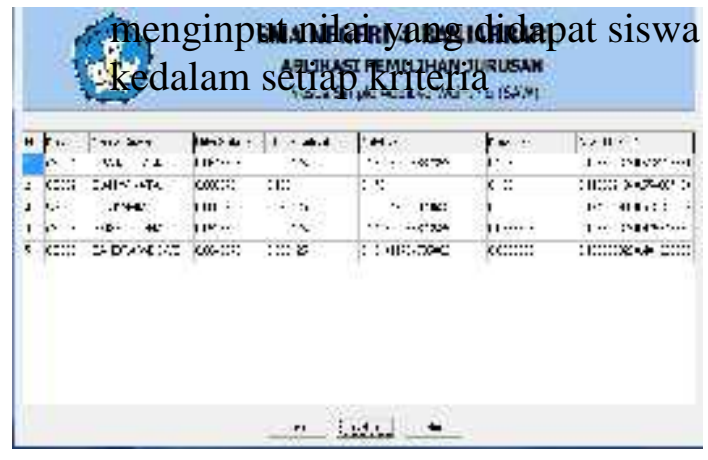

Gambar 3.3 Menu Login

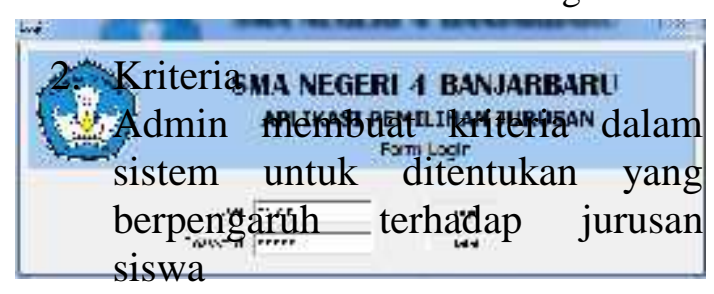

Gambar 3.5 Pembobotan SAW

4. Proses SAW

Jurnal Ilmiah "Technologia" 


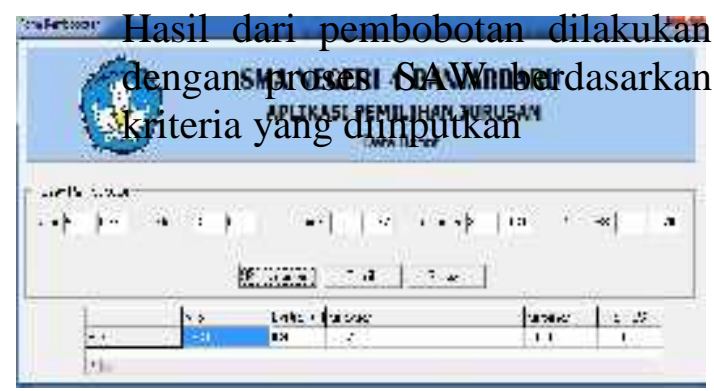

Gambar 3.6 Proses SAW

5. Hasil SAW

Hasil SAW merupakan akhir dari penentuan jurusan siswa baik IPA, IPS maupun Bahasa.

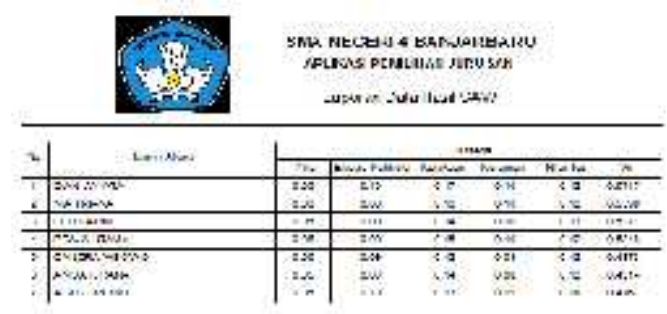

Gambar 3.7 Hasil SAW

\section{PENUTUP}

\subsection{Kesimpulan}

Berdasarkan implementasi Sistem Penentuan Keputusan pemilihan jurusan di SMA Negeri 4 Banjarbaru dapat mentukan jurusan IPA, IPS dan Bahasa. Pada proses sebelumnya mekanisme tidak ada penyaringan yang tepat, dikarenakan proses pengambilan keputusan berdasarkan subyektif oleh pihak guru atau kepala sekolah. Metode Simple Additive Weighting (SAW) dapat membantu untuk pengambilan keputusan yang memakai kriteria atau parameter yang lebih dari satu dan memberikan ke akuratan, sehingga keputusan menjadi lebih objektif.

\subsection{Saran}

Sistem Penentuan Keputusan pemilihan jurusan di SMA Negeri 4 Banjarbaru menggunakan metode SAW masih belum sempurna, diharapkan dapat mengembangkan lebih detail terhadap jurusan dengan banyak kriteria dan gabungan metode algoritma untuk pengambilan keputusan agar tidak terbatas dan lebih fleksibel digunakan.

\section{DAFTAR PUSTAKA}

Hermanto, N. (2012). Sistem Pendukung Keputusan Menggunakan Metode Simple Additive Weighting (Saw) Untuk Menentukan Jurusan Pada Smk Bakti Purwokerto. Semantik 2012, 52 62.

Ichwan, M. (2011). Pemrograman Basis Data: Delphi 7 \& MySQL. Bandung: Informatika.

Kusnassriyanto Saiful Bahri, W. (2008). Teknik Pemrograman Delphi (Edisi Revisi). Bandung: Informatika.

Supartha, I. K. D. G., \& Purnama, I. G. A. P. E. (2014). Sistem Pendukung Keputusan Penentuan Jurusan Pada SMK Kertha Wisata Denpasar Menggunakan Fuzzy SAW. Jurnal Nasional Pendidikan Teknik Informatika (JANAPATI), 3(2), 64-69. Supartha, I. K. D. G., \& Purnama, I. G. A. P. E. (2014). Sistem Pendukung Keputusan Penentuan Jurusan Pada SMK Kertha Wisata Denpasar Menggunakan Fuzzy SAW. Jurnal Nasional Pendidikan Teknik Informatika (JANAPATI), 3(2), 64-69. Widodo, P. P. (2011). Menggunakan UML. Bandung: Informatika.

Yusuf, F., Kom, S., Darmawan, E., Kom, S., \& Friatna, F. (2013). Implementasi Metode Weighted Product Pada Sistem Pendukung 
Keputusan Untuk Menentukan Penjurusan Di Sekolah Menengah Atas (Studi Kasus Di Sma Negeri 1 Lebakwangi). Sistem Pendukung Keputusan Untuk Menentukan Penjurusan. 